\title{
Uma política externa engajada: a diplomacia do governo Lula
}

\section{PAULO ROBERTO DE ALMEIDA*}

\section{Comparando duas diplomacias: os governos FHC e Lula em perspectiva}

A política externa do governo Luiz Inácio Lula da Silva é, provavelmente, a vertente da atividade governamental que mais reflete as antigas propostas e as posições tradicionais do Partido dos Trabalhadores. Com efeito, nem na política econômica, nem em ações setoriais tomadas até o momento pelos vários ministérios é tão nítida a "filiação genética" com posições ostentadas historicamente pelo PT - tal como refletidas em teses programáticas e em declarações e textos de seus líderes ao longo dos últimos vinte anos -, como nas iniciativas tomadas desde o início de 2003 no âmbito da diplomacia. Em outros termos, é nas relações exteriores e na sua política internacional que o governo do presidente Lula mais se parece com o discurso do PT. Não há, nessa afirmação, nenhuma revelação inédita para o observador bem informado, nem constitui ela uma elaboração analítica dotada de grande originalidade: trata-se de um fato corroborado por uma simples observação jornalística do ativismo diplomático exibido desde o início do governo Lula.

Do ponto de vista da legitimação política da ação diplomática, grande parte do discurso governamental, não apenas nessa área, mas principalmente nessa vertente, tem se dedicado a enfatizar as diferenças em relação às posições e políticas do governo anterior, geralmente para demarcar linhas de ruptura e evidenciar a nova postura governamental. A diplomacia do governo Lula já foi chamada de "ativa e altiva" por seu próprio chefe, o embaixador Celso Amorim, e certamente ela traz a marca de um ativismo exemplar, evidenciado em dezenas, ou mais propriamente centenas, de viagens e visitas bilaterais do chefe de governo e seu chanceler, no Brasil e no exterior, ademais da intensa participação, executiva e técnica, em quase todos os foros relevantes abertos ao engenho e arte da diplomacia brasileira, conhecida por ser extremamente profissional e bem preparada substantivamente. A maior parte das novas iniciativas se situa na vertente das negociações comerciais internacionais e na busca de uma ativa coordenação política

\footnotetext{
Rev. Bras. Polít. Int. 47 (1): 162-184 [2004]

* Diplomata de carreira. As opiniões e os argumentos expressos no presente artigo são os do seu autor e não representam posições ou políticas do governo brasileiro ou de seu ministério das relações exteriores.
} 
com atores relevantes da política mundial, geralmente parceiros independentes no mundo em desenvolvimento, com destaque para a Índia, a África do Sul e a China, ademais dos países vizinhos da América do Sul.

Muitas dessas novas iniciativas constituem, na verdade, desdobramentos e reforço de ações já em curso na administração anterior, embora com nova roupagem e novas ênfases conceituais, o que as colocaria mais na linha da "continuidade" do que na de "ruptura". Exemplos podem ser citados na opção preferencial pelo Mercosul e pelos acordos no contexto sul-americano, assim como no desenvolvimento de relações mais próximas com aqueles mesmos parceiros identificados no parágrafo anterior. Entretanto, as inovações conceituais e as diferenças práticas são evidentes, o que cabe enfatizar desde já, e a isso se dedica o presente ensaio.

Um exercício desse tipo não pode ser efetuado apenas no plano da retórica, mas certamente que o discurso partidário em temas de política internacional tanto o anterior, do PT, como o atual, do governo liderado pelo partido - comanda a ação governamental, mais do que em qualquer outra área institucional. Esse discurso já enfatiza, desde muitos anos, essas alianças preferenciais com parceiros do Sul, como uma análise perfunctória permitiria revelar. Não pretendo, contudo, voltar a examinar as idéias e posições adotadas pelo PT em matéria de política externa e de relações internacionais do Brasil, tanto porque já o fiz em ocasiões anteriores e ainda no período recente. ${ }^{1}$

Tendo em vista que a atual diplomacia - tanto do lado do Itamaraty, como pelo lado da assessoria de relações internacionais da presidência da República enfatiza, precisamente, suas linhas de ruptura em relação ao anterior governo do presidente Fernando Henrique Cardoso (1995-2002), pode ser sugestivo traçar algumas linhas dessa política externa numa perspectiva comparada com aquela implementada pela administração precedente. Efetuei, em artigo para obra coletiva, um relato factual e uma breve análise da diplomacia do governo anterior, terminando por chamar a atenção para algumas das linhas de ação do presente governo do presidente Lula. ${ }^{2}$ Caberia agora ampliar o exercício comparativo, com uma descrição sistemática dos elementos de ruptura e de continuidade entre as duas diplomacias. Pretendo fazê-lo de modo resumido, sumariando, simetricamente, posições de política externa e práticas diplomáticas respectivas dos dois governos, sem no entanto adentrar em elaborações conceituais ou digressões analíticas muito detalhadas.

Um exercício comparativo desse gênero, para tornar mais evidentes eventuais linhas de ruptura, corre o risco de apresentar caracterizações estereotipadas, o que foi aqui feito deliberadamente, como forma de melhor enfatizar as diferenças entre as duas administrações. ${ }^{3}$ Para melhor fluidez do texto, contudo, não serão apresentadas - com uma única exceção as "provas documentais" ou os "suportes declaratórios" para cada uma das caracterizações que são oferecidas 
em apoio de meus argumentos, mas as evidências factuais podem ser buscadas nos próprios sites oficiais e nos boletins eletrônicos que se dedicam ao seguimento da política externa e das relações internacionais do Brasil, a começar pelo principal instrumento nessa área, o do Relnet (http://www.relnet.com.br). ${ }^{4}$

O presente exercício comparativo também dá seqüência a esforços similares ou preliminares de reconstrução histórica, baseados num seguimento tanto quanto possível próximo das posições e declarações do Partido dos Trabalhadores em matéria de política internacional e de relações exteriores do Brasil, seja em seus documentos fundacionais, seja por ocasião de campanhas presidenciais, que costumam revelar de modo mais claro o pensamento dos dirigentes em questões internacionais.

O exercício comparativo aqui desenvolvido não se pretende exaustivo, tendo selecionado apenas algumas áreas de interesse para a diplomacia brasileira. Depois de uma caracterização geral das diferenças entre as duas administrações, as áreas selecionadas para um breve contraste foram as seguintes: multilateralismo e Conselho de Segurança das Nações Unidas (CSNU); OMC, negociações comerciais multilaterais e cooperação Sul-Sul; terrorismo; globalização e capitais voláteis; FMI e política de condicionalidades; Brasil como líder; América do Sul; Mercosul; Argentina; Europa; relação com os Estados Unidos e Alca. Uma seção final abordará questões funcionais, isto é, os instrumentos diplomáticos e as características gerais das políticas externas dos dois governos.

Procurei evitar, tanto quanto possível, julgamentos de valor ou apreciações qualitativas sobre os impactos internos e externos das duas diplomacias, tanto porque os períodos não são diretamente comparáveis e os resultados das iniciativas correntes não podem, ainda, constituir objeto de balanço. Caberia, oportunamente, ampliar e tornar mais rigoroso, tanto metodologicamente quanto substantivamente, o presente exercício, que buscou tão somente evidenciar os principais elementos que deveriam integrar um esforço de comparação minuciosa e dotada de suporte documental. A rigor, uma análise desse tipo exigiria, porém, certo recuo histórico e uma investigação mais acurada sobre o significado e as consequiências de determinadas iniciativas de política externa tomadas por cada um dos presidentes, em suas administrações respectivas. Pelo menos no que se refere ao governo Lula, decorridos apenas dezesseis meses de sua inauguração, parece ser ainda muito cedo para oferecer uma avaliação desse tipo.

\section{O que distingue a política externa de Lula da do governo FHC?}

Sem dúvida alguma, do ponto de vista da forma, a diplomacia do governo Lula ostenta um ativismo exemplar, representado por um intenso programa de diplomacia presidencial (ver lista cronológica de viagens e visitas recebidas, em anexo a este ensaio), complementado por um ainda mais ativo circuito de contatos, 
encontros, viagens de trabalho e conversações a cargo do chanceler e, de maneira algo inédita para os padrões do Itamaraty, do próprio Secretário-Geral das Relações Exteriores, funcionário normalmente (e tradicionalmente) dedicado às lides administrativas e aos assuntos de "economia doméstica" da Casa. Tanto o ministro Celso Amorim, como seu principal auxiliar, embaixador Samuel Pinheiro Guimarães, têm conduzido uma das fases mais dinâmicas da diplomacia brasileira em qualquer época histórica. São obviamente divergentes muitas das análises e avaliações que se fazem sobre o mérito relativo de cada uma das iniciativas tomadas por esses responsáveis (assim como pela própria assessoria presidencial), sobre a orientação geral imprimida à política externa, assim como sobre o desempenho efetivo dessa diplomacia inovadora em termos de aumento do "bem-estar" nacional ou do prestígio internacional do País, mas não se pode deixar de reconhecer seu caráter dinâmico e "multi-presencial".

Do ponto de vista do conteúdo, a diplomacia do governo Lula apresenta uma postura mais assertiva, mais enfática em torno da chamada defesa da soberania nacional e dos interesses nacionais, assim como de busca de alianças privilegiadas no Sul, com ênfase especial nos processos de integração da América do Sul e do Mercosul, com reforço conseqüente deste no plano político. Tudo isso não deve surpreender os observadores mais argutos, pois que essas propostas figuram nos documentos do PT há praticamente vinte anos, por vezes nos mesmos termos e estilo (até na terminologia) que os atualmente proclamados, coincidindo, portanto, com a política externa praticada pelo governo Lula.

No que se refere à agenda diplomática propriamente dita, pode ser ressaltada a postura essencialmente crítica assumida em relação à globalização e à abertura comercial, com um maior empenho na reafirmação das posições tradicionais do Brasil em matéria de negociações comerciais (busca de acesso aos mercados dos países desenvolvidos, com a manutenção dos mecanismos que favorecem países em desenvolvimento, não engajamento em demandas de liberalização que possam representar comprometimento do que foi chamado de capacidade nacional de estabelecer políticas nacionais e setoriais de desenvolvimento e de autonomia tecnológica), bem como uma definição contrária - também tradicional no PT - à conhecida "fragilidade financeira externa", com a implementação conseqüente de políticas que permitam a produção de saldos comerciais e não aprofundem a dependência de capitais estrangeiros na frente econômica externa.

No plano político, é evidente o projeto de reforçar a capacidade de "intervenção" do Brasil no mundo, a assunção declarada do desejo de ocupar uma cadeira permanente num Conselho de Segurança reformado e a oposição ao unilateralismo ou unipolaridade, com a defesa ativa do multilateralismo e de um maior equilíbrio nas relações internacionais. No plano econômico, trata-se de buscar maior cooperação e integração com países similares (outras potências médias) e vizinhos regionais. 


\section{Contrastes, confrontos e coincidências entre as duas diplomacias}

(a) Multilateralismo e Conselho de Segurança das Nações Unidas

O governo Fernando Henrique Cardoso foi caracterizado por um multilateralismo moderado e atribuiu grande ênfase ao direito internacional, mas também evidenciou uma aceitação tácita do princípio dos "mais iguais", isto é, a existência de grandes potências e seu papel no sistema internacional. O governo do presidente Luiz Inácio Lula da Silva ostenta um forte multilateralismo e defende a soberania e a igualdade de todos os países com maior ênfase retórica do que tinha sido o caso na anterior administração. Enquanto FHC buscou desenvolver relações políticas com outras potências médias, Lula persegue uma estratégia de alianças com outras potências médias e economias emergentes.

No que se refere à reforma da Carta das Nações Unidas, até por querer preservar um patamar de bom entendimento com a Argentina, como revelado em depoimento do presidente FHC ao autor, ${ }^{5}$ seu governo manteve o Brasil numa situação de candidato não-insistente a uma cadeira permanente no CSNU, ao passo que o governo Lula atribui grande prioridade à conquista dessa cadeira, tendo recolhido apoios substanciais a essa pretensão - inclusive de membros do próprio CSNU - desde o início da nova gestão.

Se essa mudança de postura for aceita no plano multilateral e se for factível de ser implementada no plano prático, o Brasil passará certamente a ser mais ouvido no plano internacional. A contrapartida obrigatória é a necessidade de o País estar em condições de assumir novas e maiores responsabilidades no mesmo contexto, em termos de segurança, de assistência humanitária e de cooperação ao desenvolvimento com países mais pobres. Isso significa maiores encargos financeiros e humanos, tanto no plano bilateral, como regionalmente e no âmbito da ONU. Presume-se, também, que o governo Lula já avaliou se sua capacidade militar é compatível com essas novas responsabilidades.

\section{(b) OMC, negociações comerciais multilaterais e cooperação Sul-Sul}

No que se refere à $\mathrm{OMC}$, ambos os governos continuam a tradicional política de participação plena nas negociações comerciais multilaterais. Essa postura foi seguida pelo Brasil desde o início do sistema multilateral de comércio, mas o ativismo da diplomacia do governo Lula nessa área traduziu-se, pouco antes da reunião ministerial de Cancun (setembro de 2003), na formação do G-20, um grupo de países interessados no fim dos subsídios internos e das subvenções às exportações de produtos agrícolas e em um maior acesso aos mercados dos tradicionais protecionistas do Norte.

Em outras áreas, pode-se registrar uma postura de interdependência econômica e de relativa abertura ao investimento direto estrangeiro seguida pelo 
governo FHC, em contraste com a afirmada defesa da soberania econômica nacional e de políticas setoriais de desenvolvimento no governo Lula. Como já referido anteriormente, o governo FHC dedicou-se a um diálogo, mas não a uma real coordenação com os países do Sul, ao passo que o governo Lula traçou um grande arco de alianças estratégicas que está evidenciado sobretudo na formação do G-3, com a África do Sul e a Índia (designado de "Fórum de Diálogo Índia, Brasil e África do Sul").

Uma análise das possibilidades de entendimentos concretos a serem alcançados por esse novo bloco formado pelo Brasil com a África do Sul e a Índia deixa algumas dúvidas quanto ao seu conteúdo específico, uma vez que estes países estão desigualmente inseridos no jogo estratégico internacional, com agendas regionais e mundiais próprias, que podem coincidir em alguns pontos com a do Brasil atual (o não-hegemonismo, por exemplo), mas não necessariamente em todos. Brasil e África do Sul não são potências nucleares e não têm, a rigor, pendências com os vizinhos ou ameaças estratégicas perceptíveis, diferente dos perigos (supostos ou reais) que ameaçam a segurança da Índia.

O mesmo poderia ser dito em relação aos dois outros países com os quais se busca uma concertação política, econômica e até estratégica: a China e a Rússia. $\mathrm{O}$ estatuto de grandes potências de ambos torna problemática qualquer tentativa de coordenação política, além das legítimas aspirações em relação ao desejo de aprofundar os laços econômicos, tecnológicos e de cooperação técnica. A noção de um "bloco" entre o Brasil, a África do Sul e a Índia, qualquer que seja a acepção emprestada a esse termo (militar, política ou econômica), pode assim ser prematura. Pode-se, em contraste, reforçar o diálogo e a cooperação na busca de objetivos comuns, o que se alcança em questões pontuais que não serão necessariamente as mesmas para todos esses países o tempo todo.

Em relação à África do Sul, pode-se, a termo, pensar na conclusão de uma aliança mais estreita do lado da defesa, para a implementação da zona de paz e cooperação no Atlântico Sul, por exemplo. Dificilmente, contudo, se logrará um acordo com as grandes potências para a renúncia de passagem, nessas águas, de embarcações nuclearmente armadas. De toda forma uma cooperação no terreno estratégico faria com que o Brasil e a África do Sul (e outros países da região) se tornassem menos dependentes, em termos de equipamentos e posicionamento estratégico, de qualquer uma das grandes potências.

\section{(c) Terrorismo}

Em matéria de luta contra o terrorismo, as posições de ambos os governos são fundamentalmente comparáveis, como revelado na seguinte seleção de pronunciamentos de cada um dos presidentes.

Para FHC, em discurso na Assembléia (parlamento) da França (em 30/10/2001), 
É preciso reagir com determinação ao terrorismo, mas ao mesmo tempo enfrentar, com igual vigor, as causas profundas e imediatas de conflito, de instabilidade, de desigualdade. (...) A barbárie não é somente a covardia do terrorismo, mas também a intolerância ou a imposição de políticas unilaterais em escala planetária.

No próprio dia dos atentados em Nova York e Washington (9/11/2001), FHC chamava a atenção para as novas ênfases da agenda internacional:

A Carta das Nações Unidas reconhece aos Estados-membro o direito de agir em autodefesa. Isso não está em discussão. Mas é importante termos consciência de que o êxito na luta contra o terrorismo não pode depender apenas da eficácia das ações de autodefesa ou do uso da força militar de cada país.

Mas ele enfatizava também que "o terrorismo não pode silenciar a agenda da cooperação e das outras questões de interesse global."

De forma similar, o presidente Lula ressaltou, em 10 de julho de 2003, que "Não será militarmente que vamos acabar com o terrorismo, nem tampouco com o narcotráfico. Vamos enfrentar isso com muito mais densidade na hora em que a gente atacar o problema crucial que é a pobreza no mundo." Ele agregou, em discurso efetuado na Assembléia Geral da ONU, em setembro seguinte, que

existe, hoje, louvável disposição de adotar formas mais efetivas de combate ao terrorismo, às armas de destruição em massa, ao crime organizado. (...) Não podemos confiar mais na ação militar do que nas instituições que criamos com a visão da História e a luz da Razão. (...) O verdadeiro caminho da paz é o combate sem tréguas à fome e à miséria, numa formidável campanha de solidariedade capaz de unir o planeta ao invés de aprofundar as divisões e o ódio que conflagram os povos e semeiam o terror.

O que se poderia observar a partir dessas declarações é que ambos os presidentes demonstraram singular desapreço pela agenda antiterrorista dos Estados Unidos (talvez excessivamente monotemática e marcada pela ênfase militar e repressiva, mas compreensível em vista da dimensão da tragédia), voltando a reafirmar seu entendimento de que o terrorismo pode e deve ser combatido prioritariamente em suas causas sociais - o que em última análise demonstraria ingenuidade de seus serviços de informação ou diplomáticos - e sua esperança de que a agenda de desenvolvimento de países como o Brasil deveria continuar a ostentar a mesma (a rigor, falta de) prioridade que antes dos atentados.

\section{(d) Globalização e capitais voláteis}

No início de seu governo, FHC chegou a comparar a globalização a um novo "Renascimento", o que foi revisto mais tarde, em vista das assimetrias reais 
da economia internacional, em especial após as crises financeiras provocadas na segunda metade dos anos 1990 pela volatilidade dos capitais. A esse propósito, ele chegou a enviar cartas para os líderes do G-7 recomendando a adoção de mecanismos inibidores das turbulências financeiras, que também afetaram o Brasil a partir de 1997. Não é preciso dizer que esses líderes em nenhum momento declararam sua disposição em voltar atrás na ampla liberalização conduzida pela maior parte dos países desenvolvidos em relação aos movimentos de capitais financeiros. Em contraste com essa disposição para reformar aspectos específicos da arquitetura financeira internacional, o candidato do PT e alguns expoentes associados ao governo Lula proclamavam uma mensagem basicamente similar àquela veiculada pelo Foro Social Mundial, no sentido de que "um novo mundo (seria) possível", com uma condenação de princípio da globalização capitalista. Essa postura foi obviamente revista na condução prática da política econômica externa do governo Lula.

Em termos de foros abertos a cada uma das personalidades, FHC era muito bem visto em Davos e mantinha relações cordiais com vários líderes regularmente convidados para o Foro Econômico Mundial, realizado anualmente naquela cidade da Suíça oriental. Obviamente, seu nome não era sequer cogitado para falar no foro de Porto Alegre, cuja atitude em relação a seu governo era, também obviamente, de condenação sem apelo, já que identificado com as forças do neoliberalismo e da globalização capitalista. Lula, em contraste, mantinha, na fase preliminar ao governo, uma postura de sim enfático a Porto Alegre e de um sonoro não a Davos. Depois, buscando um diálogo realista com os dois mundos, ele realizou a proeza de falar (em janeiro de 2003, no início de seu governo) aos participantes de Porto Alegre e dirigir-se, logo em seguida, aos "capitalistas" de Davos, mantendo substancialmente o mesmo discurso nos dois foros. Ele também foi convidado a reunir-se (em junho de 2003, em Evian) com os líderes do G-8, a convite do presidente francês Jacques Chirac e levou a mesma mensagem que repetiria três meses mais tarde na ONU: a necessidade de combater a fome e a pobreza mundial, mediante um fundo a ser alimentado se possível com a taxação de capitais voláteis ou sobre o comércio de armas.

Com respeito às políticas preconizadas em cada um dos universos, pró- e antiglobalização, parece claro que FHC ostentava uma aceitação implícita do Consenso de Washington e de suas principais premissas, enquanto Lula e o PT nunca esconderam sua recusa explícita ao Consenso de Washington. Um esforço de resposta conceitual e de oferecimento de uma nova agenda, inclusive em direção aos demais países da América Latina, foi feito com o novo governo argentino do presidente Nestor Kirchner, ao ser proposto um "consenso de Buenos Aires", mas o documento assinado em outubro de 2003 não passou de recomendações gerais de políticas econômicas e sociais. ${ }^{6}$ No plano mais geral dessas políticas, também parece claro que FHC privilegiou sempre a sustentabilidade econômica 
de seu governo, ao passo que Lula, pelo menos no início, tornou patente sua preferência pela sustentabilidade social das medidas do governo. Na prática, não foram registradas diferenças notáveis entre os dois governos em termos de orientações econômicas, inclusive externas, em especial no que se refere ao FMI, mas nesse terreno a retórica diplomática se afasta notavelmente do discurso oficial da equipe econômica, a ponto de se poder questionar a unidade do verbo e da ação governamental.

\section{(e) FMI e condicionalidades}

A administração FHC, sobretudo seu ministro da economia Pedro Malan, realizou uma abordagem não-ideológica das relações com o FMI, a ele recorrendo quando isso se tornou inevitável, na seqüência das crises financeiras que abalaram os países asiáticos e a Rússia (mais especificamente a partir de outubro de 1997 e em agosto de 1998). Não houve nenhum obstáculo político à manutenção de relações cooperativas com o FMI durante as várias fases dessas turbulências financeiras e três pacotes de apoio preventivo foram assinados pelo governo: em 1998 (por um valor de US \$ 41,5 bilhões, com a participação de vinte países), em 2001 (um acordo stand-by clássico, por um valor de US\$ 15 bilhões) e em 2002 (já com o apoio explícito do candidato do PT, pelo valor inédito na história do FMI de US\$ 30 bilhões).

O FMI constituía, como é sabido, um dos principais objetos da demonologia econômica do PT, durante toda a sua história, opondo-se o partido e o seu candidato a qualquer acordo que "limitasse a soberania brasileira". Durante a campanha eleitoral, uma mudança de postura foi observada, logrando-se, depois, uma aceitação relutante e a manutenção da desconfiança (embora silenciosa). Com a postura pragmática adotada pelo ministro da Fazenda Antonio Palocci, o PT chegou até a aprovar o princípio da renovação do acordo concluído em 2002, ainda que sob protestos de setores expressivos do partido e uma postura discreta do candidato presidencial. Uma carta de aceitação formalizada na época (agosto) acusava em todo o caso o governo FHC de irresponsabilidade econômica e confirmava o desejo de mudar a política econômica desde o primeiro dia de um governo do PT. Na realidade, o governo Lula conviveu (de má vontade) com o acordo com o FMI e, no momento decisivo, resolveu reconduzir o pacote de apoio preventivo como uma garantia de estabilidade macroeconômica e de solvabilidade externa.

No geral, FHC não relutou em aceitar o tipo de constrangimento real ao exercício das políticas econômicas nacionais trazido pelos acordos com o FMI (traduzido em especial na necessidade de se garantir um superávit primário), decidindo mantê-los enquanto fosse necessário. Em contraste, a postura do governo Lula sempre foi a de tolerar esses acordos apenas e tão somente enquanto fosse absolutamente indispensável para o equilíbrio das contas externas, empregando 
todo tipo de argumento político ou econômico para justificar a manutenção do constrangimento. Na prática, mais uma vez, não ocorreu contraste significativo em relação à administração precedente.

\section{(f) Brasil como líder}

A assunção de qualquer papel do Brasil como líder era visto, por FHC, como o resultado da gradual preeminência econômica do País e deveria em princípio ser limitado à região, em vista da limitação dos recursos efetivamente disponíveis para a ação externa do Estado (em termos financeiros, obviamente, mas também militares e diplomáticos). Para o governo Lula, visivelmente, trata-se de um dos grandes objetivos políticos, e não necessariamente limitado apenas à região. Enquanto FHC modulava esse objetivo em função das percepções dos parceiros regionais (a começar pela Argentina), Lula parece acreditar que esse papel pode ser conquistado com o ativismo diplomático e as alianças estratégicas que estão sendo desenvolvidas com os parceiros já citados anteriormente. FHC tinha consciência dos limites estratégicos e da real capacidade econômica do Brasil, ao passo que para o governo Lula não parece existir limitações estruturais (orçamentárias e militares) a tal pretensão. Na prática, o exercício da liderança se revelou mais difícil do que antecipado idealmente nos discursos para consumo público.

O elemento da liderança proclamado pelo novo governo também aparece como potencialmente implementável, por exemplo, nas relações com os países africanos (em especial os lusófonos), terreno no qual o governo FHC limitava-se a proclamar uma bem intencionada política de cooperação (não imediatamente seguida de ações). O governo Lula não apenas passou a proclamar sua política de ativa solidariedade com a África (quase que como uma espécie de reconhecimento pelos séculos de tráfico, de escravidão e de exclusão interna dos “afro-brasileiros"), mas também prometeu passar à ação concreta. Lula realizou, no final de 2003, um bem sucedido périplo diplomático pela África austral, cuja conseqüência mais visível foi o estreitamente de relações com a República da África do Sul. Os demais países visitados, entretanto, em especial Angola, Moçambique e São Tomé, esperam a materialização da generosidade concreta do Brasil.

\section{(g) América do Sul}

Para FHC, as relações com os países da região eram definidas como estratégicas, daí uma grande ênfase retórica em seu governo, mas de fato poucas iniciativas foram implementadas durante o primeiro mandato (1995-1998), a não ser uma bem sucedida intervenção no conflito fronteiriço entre o Peru e o Equador. Um acordo comercial entre o Mercosul e a CAN foi várias vezes anunciado, mas 
permaneceu inconcluso. Por outro lado, o conceito de uma área sul-americana de livre-comércio (Alcsa), lançado na anterior administração de Itamar Franco (cujo chanceler foi Celso Amorim), foi aparentemente esquecido pelo ministro Luiz Felipe Lampreia.

Lula, em contraste, não apenas confirmou que essas relações eram estratégicas, mas também tomou diversas iniciativas políticas para traduzir a retórica em realidade, em especial visitando ou recebendo, bilateralmente, todos os chefes de Estado da região (inclusive o chefe progressista da oposição ao governo constituído do Uruguai, em encontro que se processou por ocasião de uma das reuniões de cúpula do Mercosul). Lula também impulsionou a retomada das negociações regionais de comércio para um acordo entre a CAN e o Mercosul, mas as dificuldades para a formação de uma área de livre comércio permanecem as mesmas que no período anterior, em vista do grande poder de atração exercido pelos Estados Unidos (tanto no âmbito da Alca, como à margem do esquema multilateral).

No plano da integração física, FHC patrocinou em seu segundo mandato (mais precisamente em setembro de 2000) um encontro em Brasília de todos os chefes de Estado da América do Sul, da qual resultaria o esquema da Iirsa (iniciativa de integração física regional), com participação do BID, esquema parcialmente aceito pelo governo Lula, que no entanto preferiu tomar iniciativas (ainda não concretizadas) de financiamento bilateral pelo BNDES. Um segundo encontro realizado em 2002 no Equador, com a presença de FHC, não modificou substancialmente os projetos de cooperação, e não se sabe se o esquema iniciado no governo anterior será continuado no governo Lula. Em todo caso, a liderança proclamada na região recebeu menor carga retórica no segundo ano da administração Lula, talvez em virtude de uma estratégia não de todo feliz no plano das negociações hemisféricas, ou em função das reais limitações de recursos enfrentadas pela diplomacia na materialização dos projetos concebidos.

De modo geral, em ambos os governos se buscou e se busca manter relações cooperativas com todos os países da região, inclusive com os Estados Unidos. A diplomacia profissional e os presidentes proclamam a reintegração de Cuba ao concerto americano e gostariam de poder contribuir para a pacificação política e militar dos países vizinhos, sem que o Brasil disponha, como parece evidente, de condições de intervenção econômica e militar (ademais do diálogo político) para fazer com que tais objetivos se concretizem. Por outro lado, há uma desconfiança de princípio, em nos meios militares, de que a atuação dos Estados Unidos busca assegurar a preservação de sua hegemonia e influência na região, o que de certa forma poderia limitar a capacidade de influência do Brasil. Não ficou muito explícito, em nenhum dos governos, que condições, meios ou instrumentos poderiam ser mobilizados, pelo Brasil, ademais dos tradicionais recursos verbais da diplomacia, para conduzir a um desfecho a crise de governança em alguns 
países vizinhos e a pacificação da tragédia colombiana, que apresenta nítidas repercussões regionais. O subcontinente convive com diversas crises, geralmente internas aos países, algumas regionais e remanescentes de antigos tratados de fronteiras (Venezuela-Guiana, por exemplo), que não necessariamente podem ser administradas pelos mesmos métodos em cada caso.

\section{(h) Mercosul}

O Mercosul constitui, desde o governo Sarney, uma das mais importantes prioridades da diplomacia brasileira, o que foi confirmado seguidamente desde então. Ele era visto pela administração FHC como uma base possível para a integração econômica da região com o mundo e conducente ao fortalecimento das relações econômicas na região e fora dela. Para Lula, o Mercosul constitui, manifestamente, a prioridade mais importante da diplomacia brasileira e um plano para o seu reforço e aprofundamento até 2006 foi apresentado aos demais parceiros: trata-se da implementação de normas já adotadas ou da finalização de um conjunto de outras ações e medidas já negociadas.

O presidente Lula ressaltou diversas vezes a importância estratégica do Mercosul para o seu governo, no que poderia constituir uma espécie de base material para a união política da América do Sul. A região, nessa visão, deveria estar livre de influências externas, obviamente do grande irmão do Norte, e das limitações hegemônicas por ele impostas (notadamente no âmbito da Alca). O Mercosul atuaria, nesse caso, como uma fortaleza defensiva contra as investidas do império, o que parece não ter sido muito bem acolhido pelos demais países da região, que mantêm com os Estados Unidos relações privilegiadas à altura de 30 ou $40 \%$ de suas exportações e que dependem de seus capitais e tecnologia (tanto quanto o Brasil, aliás).

De forma geral, os temas econômicos e comerciais tiveram, para FHC, prioridade sobre os demais na agenda do Mercosul, enquanto para Lula o social e o político parecem ter assumido a precedência no processo de integração. Os progressos, em todo caso, têm sido mais proclamados do que efetivos, em vista de dificuldades econômicas persistentes em cada um dos países. O Mercosul passou a ser buscado, talvez, não mais como um meio para realizar objetivos mais gerais de política externa ou de "economia política", mas aparentemente como um fim em si mesmo, dispondo-se o Brasil a assumir os custos e responsabilidades dessa ênfase acrescida no papel do Mercosul.

De forma geral, a integração sul-americana já fazia parte da agenda diplomática anterior, mas ela foi agora particularmente reforçada, com o envolvimento direto de um de seus principais patrocinadores, o Secretário-Geral do Itamaraty em pessoa. Passou-se também a dar maior importância aos aspectos não diretamente comerciais da integração, como a coordenação de políticas 
macroeconômicas (inclusive o já referido projeto de uma futura moeda comum) e as vertentes social e política (reforço da representação social, parlamento eleito por voto direto), o que pode, paradoxalmente, representar novos investimentos num edifício integracionista ainda carente de vários alicerces econômicos e comerciais para a realização plena do mercado comum, objetivo ainda defendido pelos países-membro.

A falta de recursos financeiros pode representar um impedimento para a realização de muitas das iniciativas vinculadas à integração física, mas o mais importante parece ser a fragilidade econômica atual dos países-membro, o que torna difícil a derrubada das últimas barreiras internas à consecução da zona de livre comércio, ao acabamento da união aduaneira e à implementação do mercado comum. Segundo algumas propostas, as assimetrias internas teriam de ser superadas mediante programas compensatórios, num esquema similar ao dos fundos compensatórios europeus, o que também é difícil numa conjuntura de fragilidade econômica como a que vivem os países-membro.

\section{(i) Argentina}

O país platino sempre foi, para FHC, "um" parceiro estratégico, ao passo que Lula o considera como "o" parceiro estratégico. FHC buscava lograr uma coordenação política e econômica com o vizinho mais importante, mas dentro de certos limites, isto é, sem comprometer a gestão independente das políticas macroeconômicas e setoriais do Brasil. Da mesma forma, ele mantinha posições cautelosas sobre a moeda única do Mercosul (que seria basicamente um projeto bilateral com a Argentina), declarada importante, mas sem que medidas efetivas fossem adotadas nessa direção. Em todo caso, consciente dos problemas reais, FHC avançou mais de uma vez a idéia de um "pequeno Maastricht" no Mercosul, isto é, a adoção de um conjunto de requerimentos econômicos de natureza técnica (similares, talvez, aos da União Européia), previamente ao estabelecimento de algum esquema mais avançado de unificação monetária.

Lula não apenas tem mantido consultas freqüentes com a nova administração argentina sobre os mais diversos assuntos, como também vem buscando posições comuns (na Alca, por exemplo). Da mesma forma, ele vem reafirmando, talvez com menor ênfase no segundo ano, a meta da moeda comum e de uma união política no Mercosul (a começar por um parlamento diretamente eleito). Assim, ao passo que FHC parecia se conformar com a idéia de um Mercosul intergovernamental, Lula adiantou uma postura de princípio favorável à supranacionalidade, sem, contudo, manifestar-se expressamente.

O chamado "consenso de Buenos Aires" - documento bilateral com pretensões a plataforma de ação regional - parece situar-se mais no plano simbólico do que constituir-se em guia efetivo da ação setorial de cada um dos países nas 
áreas econômica e social. Em todo caso, seu papel diplomático é duvidoso e sua eficácia relativa, tanto na esfera bilateral como regional. ${ }^{77}$

\section{(j) Europa}

FHC via na Europa, pelos laços históricos e culturais, o mais importante parceiro do Brasil e do Mercosul, mas adotava uma postura realista em relação às possibilidades de abertura comercial, na qual ele reconhecia a hipocrisia da postura da União Européia em matéria de protecionismo agrícola. Também Lula reconhece na Europa um parceiro importante, mas parece também acreditar num certo papel político compensatório a ser desempenhado por países europeus em "alianças estratégicas" contra o unilateralismo dos Estados Unidos, como revelado na crise do Iraque.

Cultivando relações cooperativas com os países mais importantes da Europa, FHC não os considerava, todavia, como uma "alavanca estratégica" nas relações com os Estados Unidos. No plano comercial, por outro lado, ele procurava obter as maiores vantagens possíveis dos dois processos regionais de liberalização comercial, mas apenas Lula parece ver no acordo comercial entre o Mercosul e a UE maiores benefícios potenciais do que aquele negociado com os Estados Unidos e demais parceiros para a realização de uma Alca.

\section{(k) Relação com os Estados Unidos}

Essa relação era definida, por FHC, como essencial e cooperativa: não obstante as boas relações políticas, mantinham-se os desacordos setoriais, a maior parte em questões de comércio e propriedade intelectual. Para Lula, igualmente, essa relação é importante, mas não é considerada essencial para o atingimento dos objetivos diplomáticos brasileiros (e talvez sua consecução se coloque até mesmo em oposição à vontade do "império"). Em várias áreas são nítidos os desacordos, tanto políticos quanto econômicos. FHC tendia a enfatizar a cooperação bilateral, ao passo que, no plano da política mundial, Lula busca concretamente a multipolaridade.

$\mathrm{Na}$ administração $\mathrm{FHC}$, vigorava uma reciprocidade moderada, ao passo que o governo Lula passou a tratar dos Estados Unidos na base da estrita reciprocidade, como evidenciado no caso da identificação de viajantes. O governo Lula certamente não é antiamericano, embora haja uma nítida postura antiamericana em diversos, talvez em amplos, setores sociais da base política do PT. Pesquisas de opinião revelam esse grau de desconfiança e de animosidade em certos meios, o que foi revelado por ocasião dos ataques terroristas nos Estados Unidos (recebidos até com certo regozijo em certos meios dessas "bases"), no caso da identificação de viajantes e na reação a matérias da imprensa americana sobre o Brasil. 
O governo Lula, de modo geral, deseja uma boa relação com os Estados Unidos, mas também busca uma política de afirmação concreta da defesa dos interesses nacionais, o que por vezes se manifesta de forma algo inusitada, como no caso do fichamento de visitantes americanos ou ainda no episódio da cassação do visto do correspondente americano do jornal New York Times. Que a opinião pública seja majoritariamente a favor desse tipo de medida, não implica, a rigor, que o governo adote medidas de questionável embasamento legal. Nesses casos, o governo pode ter desejado atender mais à opinião pública, ou aos setores antiamericanos do PT, do que aos interesses bem pensados do Brasil enquanto país aberto e democrático.

\section{(l) Alca}

O governo FHC, que seguiu o processo desde seu início, nunca ostentou grande entusiasmo a respeito desse projeto americano, mas tampouco mantinha uma oposição de princípio à tentativa de constituição de uma área de livre comércio das Américas. O PT, em contraste, sempre se opôs, de maneira até virulenta, ao que se apresentava, segundo sua visão, como um esquema velado de dominação imperial. Lula, quando candidato, falou de modo muito claro da Alca como sendo um "projeto de anexação" da América Latina pelos Estados Unidos. Um plebiscito politicamente orientado e preventivamente dirigido contra a Alca foi organizado em plena campanha presidencial por movimentos sociais (com amplo apoio de setores do PT e de sindicatos identificados com o partido), mas o PT, por óbvios motivos políticos, retirou seu patrocínio explícito, consciente dos efeitos possivelmente sensíveis no plano diplomático.

Para FHC, tal como expresso na conferência de cúpula de Québec (abril de 2001), a Alca poderia ser uma oportunidade concreta para a modernização da economia brasileira e pretendia empreender uma dura barganha sobre os protecionismos setoriais dos Estados Unidos (subsídios agrícolas, em especial), ao mesmo tempo em que propunha uma aceitação limitada dos novos temas (regras, propriedade intelectual, investimentos e compras governamentais e acesso em serviços). Lula, uma vez eleito, operou uma aceitação muito relutante do princípio do livre comércio e, uma vez no poder, passou a comandar uma barganha ainda mais dura na mesa de negociações, o que levou a vários impasses negociais (por certo facilitados pela postura intransigente dos Estados Unidos no que respeita o acesso aos seus próprios mercados e à limitação do subvencionismo agrícola). Algumas propostas lançadas pelo Brasil não chegaram sequer a ser explicitadas concretamente, como o pedido de compensações para corrigir assimetrias estruturais.

Em contraste com a administração anterior, a postura diplomática deixou o lado das negociações meramente "técnicas" para enfatizar o chamado "interesse 
nacional", com uma visão bem mais crítica das vantagens e desvantagens da liberalização comercial numa situação relativamente assimétrica com o império. Mas também se deixou a defesa do multilateralismo e do "entendimento único", que eram dois pontos enfatizados pelo Brasil anteriormente (na conferência de Belo Horizonte, por exemplo), para uma escolha pela geometria variável, pelo minilateralismo e pela liberalização à la carte, o que de certa forma é compreensível, tendo em vista a própria fragmentação e diferenciação das ofertas dos Estados Unidos no esquema da Alca. Pode-se dizer que a Alca, devido em grande medida à postura do novo governo brasileiro, "aladizou-se", com as vantagens e desvantagens desse tipo de arranjo ad hoc e parcial.

\section{Instrumentos diplomáticos e características gerais das duas diplomacias}

De modo geral, a política externa conduzida no governo FHC tinha no Itamaraty seu foco principal, sendo que até mesmo os conselheiros presidenciais eram diplomatas. No governo Lula, o Itamaraty partilha a formulação e até mesmo a execução da política externa com assessores presidenciais. No primeiro caso, a diplomacia presidencial era explícita, no segundo caso também o é, mas o próprio conceito foi recusado por sua suposta identificação com a administração anterior, sendo, portanto, implícita. FHC parecia colocar as prioridades econômicas antes de tudo, ao passo que o novo governo assume suas prioridades políticas em primeiro lugar.

Conformismo e voluntarismo talvez sejam expressões muito fortes, e certamente maniqueístas, mas elas provavelmente traduzem uma postura de "aceitar o mundo como ele é", no caso de FHC, e outra de "mudar o mundo" (como explicitado, por exemplo, na tentativa insistente de se instituir uma espécie de "Fome Zero Mundial"). FHC chegou a admitir a idéia de uma "Tobin tax" para diminuir a volatilidade e promover a cooperação multilateral em prol de uma "arquitetura financeira" renovada, mas ele nunca chegou, de fato, a lutar por essa idéia, provavelmente desaconselhado pelos assessores econômicos, que demonstraram não apenas a inocuidade da medida como seu forte viés contrário aos interesses do Brasil, um tomador de recursos nos mercados financeiros internacionais. Lula, por seu lado, apóia enfaticamente não só a proposta da "Tobin tax" como pensa promover outros instrumentos arrecadatórios e distributivos no plano mundial para lutar contra as "injustiças" remanescentes no planeta.

Em termos de coordenação política e econômica internacional, FHC sentiase à vontade no diálogo com o G-7 e mantinha uma abordagem da agenda internacional não muito diferente da do tipo da OCDE, entidade com a qual flertou no início de seu mandato. Lula não tem nenhuma inibição no diálogo com o G-8, chegando inclusive a pressionar discretamente para participar de suas reuniões, mas aprecia bem mais a coordenação como outros países em desenvolvimento 
(tendo participado, uma vez, de uma reunião do G-15), assim como entende promover alianças estratégicas com alguns deles, como já referido.

Finalmente, no que se refere aos princípios gerais sob os quais atuam as duas diplomacias, pode-se dizer que, enquanto FHC estimulava a integração do Brasil ao mundo globalizado, Lula não tem nenhuma objeção à participação do País num mundo globalizado, desde que seja feito com plena preservação da soberania nacional (o que, por outro lado, contrasta com a posição de renúncia implícita de soberania no Mercosul, em especial no caso da moeda única). FHC entretinha o desejo de uma "globalização com face humana" e Lula fala em reduzir os efeitos perversos da globalização.

No plano mais geral, FHC manteve uma abordagem tradicional da diplomacia e a via como tendo um papel acessório no processo de desenvolvimento. Lula, por sua vez, deseja promover uma política externa criativa (definida como "ativa e altiva" por seu chanceler), e acredita que ela tem um papel substantivo na conformação de um "projeto nacional". FHC entretinha um diálogo com outros líderes mundiais, buscando um melhor ambiente cooperativo para o desenvolvimento do Brasil. Lula, de seu lado, busca exercer uma liderança regional e internacional para mudar substantivamente e trazer justiça ao mundo, bem como implantar uma "nova geografia comercial". Os contornos desta não foram muito bem definidos, mas ela tem a ver com uma presença mais afirmada dos países em desenvolvimento no processo decisório em matéria de negociações comerciais e num acesso desimpedido aos mercados nos quais esses países apresentam nítidas vantagens comparativas (o que, ironicamente, significa uma aceitação plena de princípios ricardianos de outra forma recusados por economistas de esquerda).

Numa apreciação final, parece ainda prematuro adiantar possíveis consequiências dessas mudanças de estilo e mesmo de conteúdo da política externa governamental da administração Lula para o Brasil enquanto ator internacional e regional. A intenção proclamada do novo governo é a de assegurar uma maior presença do Brasil no mundo, garantir-lhe uma cadeira permanente na ONU e tornar sua voz ouvida nas decisões em torno dos grandes problemas da comunidade internacional. Uma busca mais afirmada da liderança regional pode também resultar do novo ativismo regional, mas nesse particular a liderança não pode partir apenas do desejo de quem pretende liderar, mas da aceitação consensual dos liderados presumidos. Esse ponto ainda não ficou muito claro na relação que o governo Lula pretende manter com a Argentina, que sempre declarou e entende defender sua concepção de uma relação especial com o Brasil como situada num plano igualitário, não assimétrico.

Uma avaliação mais substantiva dos resultados efetivos do novo estilo e da nova agenda de trabalho da diplomacia do governo Lula somente será possível após o término de alguns processos negociadores nos quais o Brasil se encontra presentemente engajado e tendo em vista os efeitos práticos da liderança 
proclamada e auto-assumida no plano regional. Uma coisa, porém, é certa: quaisquer que sejam os resultados efetivos da nova diplomacia, o governo Lula encontra-se moldando sua própria história, bem como a política internacional do Brasil, e disso ele tem plena consciência.

Maio de 2004

\section{Anexo \\ Uma diplomacia presidencial extremamente ativa \\ Viagens ao exterior e visitas de alto nível a Brasília, 2002-2004}

\section{2 (como presidente eleito)}

1. Diplomacia ativa: visita de cortesia à Argentina (Buenos Aires, 2 dezembro)

2. Diplomacia ativa: visita de cortesia ao Chile (Santiago, 3 dezembro)

3. Reunião a convite do presidente George Bush (Washington, 10 dezembro)

\section{3}

4. Encontro com o presidente da Venezuela, Hugo Chávez (Brasília, 2 janeiro)

5. Encontro com o primeiro-ministro da Suécia, Goran Persson (Brasília, 2 janeiro)

6. Encontro com o primeiro ministro da República da Guiné-Bissau, Marco Antonio Avelino Reis Pires (Brasília, 2 janeiro)

7. Encontro com o presidente de Portugal, Jorge Sampaio (Brasília, 2 janeiro)

8. Encontro com o primeiro ministro da Guiana, Samuel Hinds (Brasília, 2 janeiro)

9. Visita do presidente da Argentina, Eduardo Duhalde (Brasília, 14 janeiro)

10. Visita do príncipe de Astúrias, Felipe de Borbón y Garcia (Brasília, 14 janeiro)

11. Posse do presidente Lúcio Gutierrez do Equador (Quito, 16 janeiro)

12. Diplomacia ativa: constituição do "grupo de amigos" para ajudar a OEA na crise política da Venezuela (16 janeiro)

13. Diplomacia ativa: Foro Social Mundial (Porto Alegre, 24 janeiro)

14. Diplomacia ativa: Foro Econômico Mundial (Davos, 26 janeiro)

15. Visita de trabalho ao chanceler Gerhard Schroeder (Berlim, 27 janeiro)

16. Visita de trabalho ao presidente Jacques Chirac (Paris, 28 janeiro)

17. Diplomacia ativa: telefonemas e cartas a líderes das Américas e da Europa, assim como ao Papa e ao SG-UN, para encontrar uma solução política e pacífica à crise do Iraque (fevereiro e março)

18. Visita do presidente da Colômbia, Álvaro Uribe (Brasília, 7 março) 
19. Visita do primeiro-ministro do Estado Alemão de Baden Wüttemberg, Erwin Teufel (11 março)

20. Visita do primeiro ministro da Malásia, Mahatir Mohamad (Brasília, 17 março)

21. Visita da rainha Beatrix, dos Países Baixos (Brasília, 24 março)

22. Visita do presidente do Peru, Alejandro Toledo (Brasília, 11 abril)

23. Visita do presidente da Venezuela, Hugo Chávez (Recife, 25 abril)

24. Visita do presidente da Bolívia, Gonzalo Sánchez de Lozada (Brasília, 25 abril)

25. Visita do presidente do Uruguai, Jorge Battle (Brasília, 12 maio)

26. Reunião de chefes de Estado do Grupo do Rio, no Peru (Cusco, 24 maio)

27. Visita do presidente do Equador, Lucio Gutiérrez (Brasília, 27 maio)

28. Diálogo ampliado no contexto da cúpula do G-8 em Evian (França, $1^{\circ}$ junho)

29. Visita de cortesia à Organização Internacional do Trabalho (Genebra, 2 junho)

30. Visita do presidente do Conselho do Líbano, Rafik Hariri (Brasília, 10 junho)

31. Visita do presidente da Argentina, Nestor Kirchner (Brasília, 11 junho)

32. Visita do presidente de Cabo Verde, Pedro V. R. Pires (Brasília, 13 junho)

33. Reunião de cúpula do Mercosul (Assunção, 18 junho)

34. Visita aos Estados Unidos, com diversos ministros (Washington, 20 junho)

35. Visita bilateral à Colômbia (Bogotá, 27 junho)

36. Visita do primeiro-ministro da Noruega, Kjell Magne Bondevik (3 julho)

37. Visita bilateral a Portugal (Lisboa, 10-11 julho)

38. Diplomacia ativa: reunião da Governança Progressista (Londres, 13-14 julho)

39. Encontro de trabalho com o primeiro-ministro Tony Blair (Londres, 13 julho)

40. Visita bilateral à Espanha (Madrid, 15-16 julho)

41. Visita do presidente do Suriname, Runaldo Ronald Venetiaan (Brasília, 22 julho)

42. Visita do presidente da Guiana, Bharrat Jagdeo (Brasília, 30 julho)

43. Diplomacia ativa: reunião bilateral Brasil-Paraguai (Foz de Iguaçu, 16 agosto)

44. Visita do presidente do Chile, Ricardo Lagos (Brasília, 19 agosto)

45. Visita de trabalho ao presidente do Peru, Alejandro Toledo (Lima, 24 agosto)

46. Visita do presidente de Burkina Faso, Blaise Campaoré (Brasília, 3 setembro)

47. Diplomacia ativa: encontro "Combatendo o Terrorismo em Prol da Humanidade" (Nova York, 22 setembro)

48. Abertura da 58 ${ }^{\mathrm{a}}$ Assembléia Geral da ONU (Nova York, 23 setembro)

49. Diplomacia ativa: Conselho de Relações Exteriores (Nova York, 25 setembro)

50. Diplomacia ativa: doação para o fundo mundial de combate à fome e à miséria (Nova York, 25 setembro)

51. Diplomacia ativa: visita de trabalho ao México (25 setembro)

52. Visita bilateral a Cuba (Havana, 26-27 setembro)

53. Diplomacia ativa: visita da rainha Sofia, da Espanha (6 outubro) 
54. Visita do rei Harald V e da rainha Sonja, da Noruega (Brasília, 7 outubro)

55. Visita do presidente do Paraguai, Nicanor Duarte Frutos (Brasília, 14 outubro)

56. Visita bilateral à Argentina (Buenos Aires e Patagonia, 16-17 outubro)

57. Diplomacia ativa: "Consenso de Buenos Aires" (Buenos Aires, 16 outubro)

58. Visita do presidente da Ucrânia, Leonid Koutchma (Brasília, 21 outubro)

59. Diplomacia ativa: Prêmio Príncipe de Astúrias (Oviedo, Espanha, 23-24 outubro)

60. Encontro com o presidente da África do Sul, Thabo Mbeki (27 outubro)

61. Encontro com o primeiro-ministro de Cabo Verde, José Maria Neves (27 outubro)

62. Diplomacia ativa: Congresso da Internacional Socialista (São Paulo, 27 outubro)

63. Diplomacia ativa: encontros com dirigentes da Mongólia, do Montenegro, da Romênia, da Sérvia, da Polônia e da Suécia e com o ex-presidente da Nicarágua, Daniel Ortega (São Paulo, 28 outubro)

64. Visita do presidente de Governo da Espanha, José María Aznar, (Brasília, 29 outubro)

65. Visita do presidente da Finlândia, Tarja Halonen (Brasília, 31 outubro)

66. Visita bilateral a São Tomé e Príncipe (2 novembro)

67. Visita bilateral a Angola (3-4 novembro)

68. Visita bilateral a Moçambique (5 novembro)

69. Visita bilateral à Namíbia (6-7 novembro)

70. Visita bilateral à África do Sul (7-8 novembro)

71. Visita bilateral à Bolívia (Santa Cruz de la Sierra, 14 novembro)

72. XIII Cúpula Ibero-Americana de Chefes de Estado e de Governo (Santa Cruz de la Sierra, 15 novembro)

73. Visita do presidente da República Dominicana, Hipólito Mejia (Brasília, 17 novembro)

74. Visita do presidente da Guiana, Bharrat Jagdeo (Brasília, 17 novembro)

75. Visita do presidente da Bolívia, Carlos Mesa (Brasília, 18 novembro)

76. Diplomacia ativa: visita da rainha Sílvia, da Suécia (Brasília, 24 novembro)

77. Visita do presidente da Alemanha Johannes Rau (Brasília, 27 novembro)

78. Visita bilateral à Síria (3 dezembro)

79. Visita bilateral ao Líbano (5 dezembro)

80. Visita bilateral aos Emirados Árabes Unidos (7 dezembro)

81. Visita bilateral ao Egito (8 dezembro)

82. Diplomacia ativa: visita de cortesia à Liga Árabe (Cairo, 9 dezembro)

83. Visita bilateral à Líbia (10 dezembro)

84. Diplomacia ativa: reunião do G-20 (Brasília, 12 dezembro)

85. Reunião de cúpula do Mercosul (Montevidéu, 16 dezembro) 


\section{4}

86. Reunião de cúpula das Américas (Monterrey, 14 janeiro)

87. Visita bilateral à Índia (25-27 janeiro)

88. Diplomacia ativa: seminário com investidores estrangeiros (Genebra, 29 janeiro)

89. Diplomacia ativa: Reunião com Ricardo Lagos (Chile), Jacques Chirac (França) e SG-ONU Kofi Annan: discussão sobre um fundo mundial de combate à pobreza (Genebra, 30 janeiro)

90. Visita do presidente do Líbano, Emile Lahoud (Brasília, 17 fevereiro)

91. Diplomacia ativa: reunião de cúpula do G-15 (Caracas, 29 fevereiro)

92. Diplomacia ativa: $7^{a}$ reunião de cúpula Brasil-Portugal (Brasília, 7 março)

93. Visita do primeiro-ministro de Portugal, Durão Barroso (Brasília, 8 março)

94. Visita do presidente da Argentina, Nestor Kirchner (Rio de Janeiro, 15-16 março)

95. Visita do presidente da Irlanda, Mary McAleese (Brasília, 29 março)

96. Visita do vice-primeiro ministro da China, Hui Liangyu (Brasília, 19 abril)

97. Visita bilateral à China, Beijing (21-25 maio)

98. Visita bilateral à China, com grande delegação (Beijing-Xangai, 22-26 maio)

99. Diplomacia ativa: conferência de cúpula Europa-América Latina Guadalajara, México (28-29 maio)

100. Diplomacia ativa: Abertura da XI Unctad (São Paulo, 14 junho)

Fontes: Dados, em princípio exaustivos, coletados pelo autor em diversos sites oficiais (Presidência da República, Agência Brasil da Radiobrás e Ministério das Relações Exteriores), atualizados até 27 de maio de 2004. Não existe uma única informação pública, agregada e exclusiva, sobre eventos diplomáticos envolvendo o presidente da República (todos os sites citados são lacunares, incompletos e parciais).

\section{Notas}

1 Ademais de reflexões sobre as atividades e posições de política externa dos partidos políticos feitas em dois capítulos de meu livro Relações Internacionais e Política Externa do Brasil: história e sociologia da diplomacia brasileira (cuja segunda edição acaba de ser lançada pela Editora da UFRGS), efetuei um levantamento específico sobre o PT no artigo "A política internacional do Partido dos Trabalhadores: da fundação do partido à diplomacia do governo Lula", publicado na revista Sociologia e Política (Curitiba: UFPR; ISSN: 0104-4478; n. 20, junho de 2003, p. 87-102; disponível no link: http://www.scielo.br/rsocp ou em http:// www.pralmeida.org/docs/1009PolExtPT.pdf). Versão ampliada e atualizada do artigo foi oferecida no ensaio "La politique internationale du Parti des Travailleurs: de la fondation du parti à la diplomatie du gouvernement Lula", in: Denis Rolland et Joëlle Chassin (dir.), Pour comprendre le Brésil de Lula (Paris: L'Harmattan, 2004), disponível no link: www.pralmeida.org/docs/1193PRADiplomatiePT.pdf, no original em francês. 
2 Ver meu ensaio "A relação do Brasil com os ESTADOS UNIDOS: de FHC-Clinton a LulaBush”, preparado para o livro Reformas no Brasil: Balanço e Agenda, organizado por André Urani, Fabio Giambiagi e José Guilherme Reis (Rio de Janeiro: Nova Fronteira, 2004), p. 203228.

3 Alguns dos argumentos apresentados neste ensaio foram apresentados, em forma preliminar, no seminário "Brazil: Between Regionalism and Globalism: Old Ambitions, New Results?", organizado pelo Summit of the Americas Center, da Florida International University, e pelo Instituto Brasileiro de Relações Internacionais, em 4 de março de 2004, em Miami. Parte de minha exposição nesse seminário encontra-se disponível, em inglês, no seguinte link: http:// www.pralmeida.org/docs/1213bTwoForeignPol.htm.

4 Meus artigos, notas e comentários publicados no site do Relnet estão disponíveis no seguinte link: http://www.pralmeida.org/12RelnetPRA/00RelnetPRAworks.htm.

5 Cf. meu ensaio "A relação do Brasil com os ESTADOS UNIDOS: de FHC-Clinton a LulaBush”, op. cit., p. 214-215.

6 Ver a esse propósito meu artigo “"Una sombra pronto seras...': Idealpolitik e o Consenso de Buenos Aires", revista eletrônica O Debatedouro (Brasília: ano II, nº 38, 23 novembro 2003; ISSN 1678-6637), disponível no link: http://www.odebatedouro.com.br/almeida38.html.

7 Remeto novamente à minha análise desse documento, “'Una sombra pronto seras...' Idealpolitik e o Consenso de Buenos Aires", op. cit.

\section{Resumo}

Ensaio comparativo, contrastando as políticas externas das administrações Fernando Henrique Cardoso e Luiz Inácio Lula da Silva, com base em suas características gerais e nas tomadas de posição em relação a um conjunto de temas da agenda internacional, nomeadamente: multilateralismo e Conselho de Segurança das Nações Unidas; OMC, negociações comerciais multilaterais e cooperação Sul-Sul; terrorismo; globalização e capitais voláteis; FMI e política de condicionalidades; Brasil como líder; América do Sul; Mercosul; Argentina; Europa; relação com os Estados Unidos e Alca, ademais dos instrumentos diplomáticos mobilizados por cada um dos governos. Os elementos de ruptura são mais evidentes no estilo do que na substância da diplomacia brasileira, que continua a ostentar fortes traços de continuidade.

\section{Abstract}

Comparative essay, constrasting the foreign policies of Fernando Henrique Cardoso's and Luiz Inácio Lula da Silva's administrations. Besides the general features of each diplomacy, external policies and practices of each government are compared for a set issues of the international agenda, namely: multilateralism and UN Security Council; WTO, multilateral trade negotiations and South-South cooperation; terrorism; globalization and financial flows; IMF and economic policy 
requirements; Brazil as a leader; South America; Mercosul; Argentina; Europe; relationship with the United States, and FTAA, with a final section on diplomatic tools preferred by each government. Break lines are much more evident in the style than in the substance of Brazilian diplomacy, which continues to show strong features of continuity.

Palavras-chave: Diplomacia brasileira; Governo Fernando Henrique Cardoso; Governo Luiz Inácio Lula da Silva; Globalização; Regionalismo; Negociações comerciais.

Keywords: Brazilian diplomacy; Fernando Henrique Cardoso government; Luiz Inácio Lula da Silva government; Globalization; Regionalism; Trade negotiations. 